\title{
DG3173 (somatoprim), a unique somatostatin receptor subtypes 2-, 4- and 5-selective analogue, effectively reduces GH secretion in human GH-secreting pituitary adenomas even in Octreotide non-responsive tumours
}

\author{
U Plöckinger*, U Hoffmann ${ }^{1, *}$, M Geese ${ }^{1}$, A Lupp ${ }^{2}$, M Buchfelder $^{3}$, J Flitsch ${ }^{4}$, P Vajkoczy ${ }^{5}$, W Jakob ${ }^{5}$, W Saeger ${ }^{6}$, \\ S Schulz ${ }^{2}$ and C Dohrmann ${ }^{1}$ \\ Interdisziplinäres Stoffwechsel-Centrum, Charité-Universitätsmedizin Berlin, Campus Virchow-Klinikum, Augustenburger Platz 1, 13353 Berlin, \\ Germany, ${ }^{1}$ DeveloGen AG, Goettingen, Germany, ${ }^{2}$ Institut für Pharmakologie und Toxikologie, Friedrich Schiller Universität, Jena, Germany, \\ ${ }^{3}$ Neurochirurgische Klinik mit Poliklinik, Universitätsklinikum Erlangen-Nürnberg, Erlangen, Germany, ${ }^{4}$ Interdisziplinäre Endokrinologie/ \\ Hypophysenchirurgie, Universitätsklinikum Hamburg Eppendorf, Hamburg, Germany, ${ }^{5}$ Klinik für Neurochirurgie, Charité-Universitätsmedizin Berlin, \\ Campus Virchow-Klinikum, Berlin, Germany and ${ }^{6}$ Institut für Pathologie, Marienkrankenhaus, Hamburg, Germany \\ (Correspondence should be addressed to U Plöckinger; Email: ursula.ploeckinger@charite.de)
}

*(U Plöckinger and U Hoffmann contributed equally to this work)

\begin{abstract}
Objective: Somatostatin analogues (SSA) reduce autonomous GH secretion by activating somatostatin receptors (sst) 2 and 5 in 50-60\% of acromegalic patients. However, by inhibiting insulin secretion these SSA reduce glucose tolerance. DG3173 is a novel SSA with additional binding to sst4 and low insulin-suppressing activity. We investigated the effect of DG3173, including its relation to specific tumour characteristics, on GH secretion in human somatotroph adenoma cell cultures (hSA) in comparison with Octreotide.

Methods: Twenty-seven hSA were characterised immunohistochemically for their hormone- and sstexpression, granularity and pre-surgical therapy with SSA. GH was determined in supernatants of hSA treated with DG3173 or Octreotide in time- $(n=6)$ and dose-response $(n=21)$ experiments. A positive response was defined as $\mathrm{GH}$ suppression to below $80 \%$ of baseline.

Results: In the dose-response experiments DG3173 suppressed GH secretion in more adenomas than Octreotide (10/21 vs 5/21), including 38\% (6/16) of Octreotide non-responders. In responders the extent of $\mathrm{GH}$ suppression and $\mathrm{IC}_{50}$ were comparable for both SSA. The response-rate of both SSA was higher in monohormonal vs bihormonal adenomas, yet GH declined similarly in both groups. Neither pre-surgical SSA $(n=6)$ nor tumour morphology was related to the GH response. However, semiquantitative analysis indicated a small but significant negative correlation between the $\mathrm{GH}$ response to Octreotide and the immunoreactivity scores of sst 2 expression.

Conclusions: DG3173 equalled Octreotide in suppressing GH secretion in hSA. Since DG3173 suppressed GH in some Octreotide-non-responsive adenomas, its clinical effectiveness will be worth testing. Moreover, its reduced insulin-suppressive potency would make it a valuable alternative to Octreotide.
\end{abstract}

European Journal of Endocrinology 166 223-234

\section{Introduction}

Transsphenoidal surgery reduces autonomous $\mathrm{GH}$ secretion in up to $60 \%$ of acromegalic patients (1). When autonomous $\mathrm{GH}$ secretion persists post-operatively, somatostatin analogues (SSA) are the first treatment option (2). The clinically available SSA, Octreotide and Lanreotide respectively, significantly suppress GH secretion in up to $50-70 \%$ of acromegalic patients $(2,3,4)$ while strict biochemical control $(\mathrm{GH}$ $<1 \mu \mathrm{g} / \mathrm{l}$ ) is achieved in up to $33 \%$ (3). However, these SSA also suppress insulin secretion and thus negatively affect glucose homoeostasis in a significant number of patients $(3,5,6,7,8)$.

Somatostatin receptors (sst) belong to two subfamilies, SRIF-1 (sst2, sst3 and sst5) and SRIF-2 (sst1 and sst4), with different internalisation upon SSA exposure $(9,10)$. The distinct affinity profile of each SSA translates into specific pharmacological properties $(10,11,12)$. Octreotide and Lanreotide bind with a high affinity at sub-nanomolar concentration to sst 2 . They have a moderate affinity to sst 3 and sst5, and very low or absent binding to sst 1 and sst 4 (11). In one-third of acromegalic patients, who do not respond to Octreotide, 
there is diminished expression of sst $2 \mathrm{~A}$, but persistent sst5 expression (13). SOM230 (Pasireotide), a new multiligand SSA with binding to all sst except to sst4, is currently investigated in clinical trials $(14,15,16,17$, 18, 19). Nevertheless, its negative effects on glucose tolerance are even more pronounced than with Octreotide $(14,20)$. On the other hand, BIM-23A760 (Dopastatin), a chimeric molecule directed towards somatostatin (mainly sst2 and sst5) and dopamine D2 receptors $(21,22,23)$, suppresses $\mathrm{GH}$ in vitro but was ineffective when applied to acromegalic patients in clinical trials (press release 15 Dec 2010, Ipsen Pharma).

DG3173 is a heptapeptide SSA with a novel amino acid sequence and a unique cyclic backbone (24). In addition to its affinities to sst2 and sst5, DG3173, previously named PTR-3173, is the only SSA binding with nanomolar affinity to sst4 (24). mRNA for sst4 is rarely detected in human pituitary adenomas $(25,26)$ and immunohistochemical staining for sst 4 protein has given contradictory results. While no staining was reported by some investigators $(27,28)$, others detected sst4 protein in many somatotroph adenomas (29). So far the role of sst 4 in the suppression of $\mathrm{GH}$ secretion by SSA with high affinity to sst 4 has not been investigated in detail.

Furthermore, the potency of DG 3173 to inhibit GH secretion in vitro is 10.000-fold higher than its inhibition of insulin secretion (24). This low insulinsuppressing activity was also demonstrated in vivo (A Steuernagel, C Meyer, R Wehr and C Dohrmann, unpublished results). For the treatment of acromegalic patients this would be a valuable advantage, if confirmed by clinical trials.

In an explorative in vitro investigation we reported that DG3173 suppresses GH in human pituitary adenomas non-responsive to Octreotide (30). In this study, we aim to verify in a larger set of human $\mathrm{GH}$-secreting pituitary adenomas whether DG3173 results in significant control of GH secretion in vitro comparable to that achieved by Octreotide. In addition, we analysed factors that might influence the effects of SSA on GH secretion in vitro, such as pre-operative SSA treatment, co-expression of other hormones by the adenomas, vesicular granularity of the tumour tissue or the expression of sst1, sst 2 A, sst 3 , sst 4 and sst 5 respectively.

\section{Materials and methods}

\section{Patients}

We investigated 27 adenomas from acromegalic patients (female: $n=12$, median age 47 , range $32-72$ years; male: $n=15$, median age 43 , range $27-69$ years; Table 1). Acromegaly had been diagnosed by failure of the $\mathrm{GH}$ concentration to be suppressed to below $1 \mu \mathrm{g} / \mathrm{l}$ during an oral glucose load and/or an increased IGF1 concentration according to current consensus $(2,31)$.
The study was approved by the ethics committee of the Charité-Universitätsmedizin Berlin. Upon written informed consent from each patient, adenoma tissue samples were collected during surgery from three clinical sites (Neurochirurgische Klinik mit Poliklinik, Universitätsklinikum Erlangen-Nürnberg; Interdisziplinäre Endokrinologie/Hypophysenchirurgie, Universitätsklinikum Hamburg Eppendorf; Klinik für Neurochirurgie, Charité-Universitätsmedizin Berlin).

\section{Somatostatin analogues}

DG3173 acetate and Octreotide acetate were purchased from Bachem AG (Bubendorf, Switzerland). Stock solutions of $1 \mathrm{mM}$ DG3173 or $1 \mathrm{mM}$ Octreotide (net peptide, respectively) were prepared by dilution of lyophilised peptide in $37 \mathrm{mM}$ lactic acid/250 mM mannitol buffer ( $\mathrm{pH} 4.3$ ). Stock solutions were stored at $2-5{ }^{\circ} \mathrm{C}$ and protected from light until use.

\section{Adenoma tissue preparation}

A portion of each adenoma obtained at surgery was dissociated by mechanical and enzymatic methods. Depending on tumour size, $6 \times 10^{5}-3 \times 10^{7}$ tumour cells were initially cultured in DMEM supplemented with $10 \% \mathrm{FCS}, \mathrm{pH} 7.3$ and plated at a density of $1 \times 10^{5}$ or $5 \times 10^{4}$ cells/well for $60 \mathrm{~h}$. On day 4 , the cells were washed with PBS and used for the time- or doseresponse study. Collagenase type 1 was purchased from Worthington (\#CLS-1 Lakewood, NJ, USA); DNAse (\#D4138), hyaluronidase (\#H2126), Soybean Trypsin

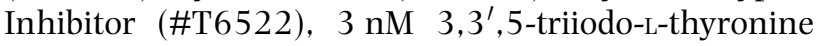
sodium salt (\#T6397), $5.5 \mathrm{mM} \mathrm{NaHCO}$ and $\mathrm{BSA}$ fat free (\#A6003) from Sigma; DMEM-low glucose, 1\% ITX and $1 \%$ glutamax from Gibco-Invitrogen; $10 \%$ FCS, $1 \%$ HEPES, PBS (\#L1820) and 1\% penicillin-streptomycin from Biochrom (Berlin, Germany).

\section{SSA treatment}

For the time-series experiments isolated cells from six different adenomas (nos 65-70, Table 1) were treated in parallel with $1 \mu \mathrm{M}$ Octreotide or $1 \mu \mathrm{M}$ DG3173 for 2, 4, 6,8 and $24 \mathrm{~h}$ respectively. For the dose-response experiments 21 tumours were used. Of these, six out of 21 patients had pre-operative SSA therapy (Table 1). During the dose-response experiments $300 \mu$ l DG3173 and Octreotide, respectively, were added in concentrations ranging from $10^{-6}$ to $10^{-12} \mathrm{M}$ and incubated for $6 \mathrm{~h}$. At the time points indicated the supernatant was carefully removed and stored at $300 \mu \mathrm{l}$ aliquots at $-20{ }^{\circ} \mathrm{C}$ until $\mathrm{GH}$ determination. All experiments were performed at least in quadruplicate. The investigators were blinded for the type of SSA. For some adenomas cell numbers were insufficient to setup and analyse all time points or SSA concentrations. Response was 


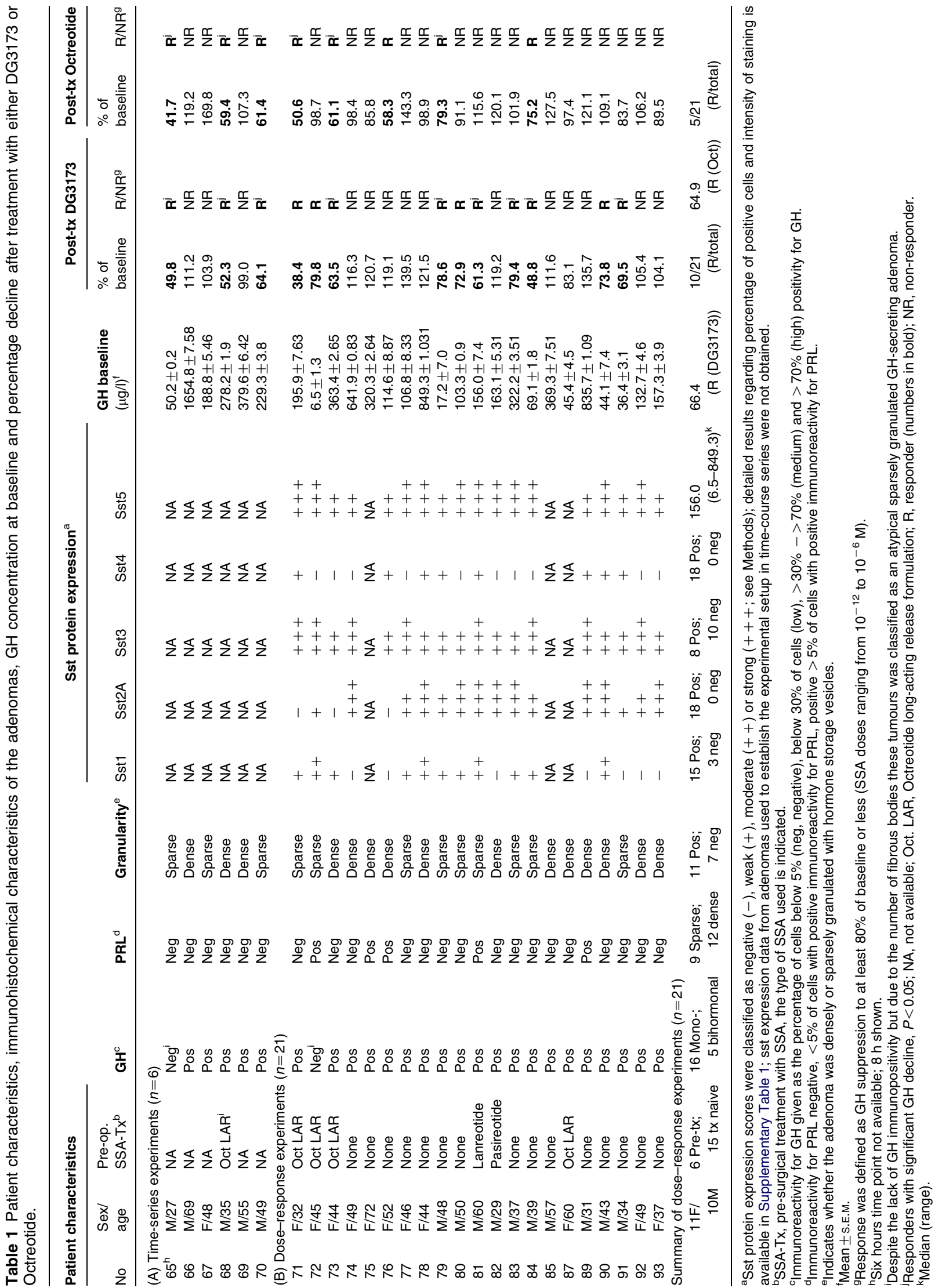


defined as GH suppression to at least $80 \%$ of baseline or less. This is in accordance with overall in vitro results reported by others (32). Furthermore, the 20\% margin covers most of the variability of GH suppression within individual tumours (mean coefficient of variation of $20.2 \%$, including variability of the $\mathrm{GH}$ assay (see below)).

\section{Human GH assay}

Human GH in pituitary adenoma cell culture supernatant was analysed by a commercial ELISA according to the manufacturer's instructions (for assay validation see Diagnostic Systems Laboratories Deutschland GmbH, Sinsheim, Germany, active ultra-sensitive human GH ELISA \#DSL-100-19100 with a LLOQ of $0.66 \mathrm{pg} / \mathrm{ml})$. Additional $\mathrm{GH}$ standards were prepared with recombinant human GH (Sigma-Aldrich). The intra-assay coefficient of variation of duplicates was $4.23 \pm 5.11$ (mean \pm S.D.).

\section{Structural and hormonal expression analysis}

All adenomas underwent histological analysis on paraffin and in part Epon sections for tumour tissue pattern and cellular details (pleomorphy, mitoses, granularity). Immunohistochemistry was performed for GH (monoclonal anti-GH, Sigma Immunochem, Zytomed, Berlin, Germany dilution 1:300), PRL (monoclonal anti-prolactin (PRL), Immunotech, Marseille, France 1:400), ACTH (polyclonal anti-ACTH, Zytomed, 1:30), TSH (monoclonal anti-TSH, Immunotech, 1:5000), FSH (monoclonal anti-FSH, Immunotech, 1:80 000), LH (monoclonal anti-LH, Immunotech, 1:60 000) and $\alpha$-subunit (monoclonal anti- $\alpha$-subunit, Immunotech, 1:1500). A positive immunohistochemical hormone expression was defined as more than $5 \%$ of the tumour cells demonstrating positive staining in any of the three grades (low, medium and high). Normal pituitaries from autopsies were used as positive control.

\section{Sst subtype expression analysis}

The rabbit monoclonal anti-sst2A, -sst3 and -sst5 antibodies UMB-1, UMB-5 and UMB-4, respectively, as well as the polyclonal anti-sst1 and -sst4 antibodies (E4317) and (4802) were generated against the carboxyl-terminal tail of the respective human sst. The identity of the peptides used for immunisations of the rabbits is given in Table 2. The MABs, as well as the polyclonal antibody (E4317), were obtained from Epitomics (Burlingame, CA, USA), the polyclonal antibody (4802) from Gramsch Laboratories (Schwabhausen, Germany). The polyclonal antibodies were purified against their immunising peptide as described by Schulz et al. (33, 34, 35, 36). Receptor-binding profiles for sst, as well as pharmacodynamic constants
Table 2 Amino acid sequences of the $\mathrm{COOH}$-terminal regions of human sst receptors used for generation of the respective antibodies.

\begin{tabular}{ll}
\hline Human sst (residues) & Sequence \\
\hline Sst1 (377-391) & ENLESGGVFRNGTCTSRITTL \\
Sst2A (355-369) & ETQRTLLNGDLQTSI \\
Sst3 (398-418) & QLLPQEASTGEKSSTMRISYL \\
Sst4 (366-388) & CQQEALQPEPGRKRIPLTRTTTF \\
Sst5 (344-364) & QEATPPAHRAAANGLMQTSKL \\
\hline
\end{tabular}

for both DG3173 and Octreotide, are given in Supplementary Table 1, see section on supplementary data given at the end of this article.

Data were only obtained from adenomas used for the dose-response experiments. Tissue specimens were fixed in $10 \%$ buffered formaldehyde and embedded in paraffin. Sections $(5 \mu \mathrm{m})$ were prepared from the paraffin blocks and floated onto positively charged slides. Immunostaining of paraffin sections was performed by an indirect peroxidase labelling method. Briefly, sections were dewaxed, microwaved in $10 \mathrm{mM}$ citric acid $(\mathrm{pH} 6.0)$ for $16 \mathrm{~min}$ at $600 \mathrm{~W}$ and then incubated with the respective anti-sst antibody overnight at $4{ }^{\circ} \mathrm{C}$. Detection of the primary antibody was performed by a biotinylated anti-rabbit IgG followed by incubation with peroxidase-conjugated avidin (Vector ABC 'Elite' kit, Vector, Burlingame, CA, USA). Binding of the primary antibody was visualised using 3-amino-9-ethylcarbazole in acetate buffer (BioGenex, San Ramon, CA, USA). Sections were then rinsed, lightly counterstained with Mayer's hematoxylin and mounted in Vectamount mounting medium (Vector Laboratories). Pancreatic islets were used as positive control for staining with antibodies to sst1, sst2A, sst3 and sst5. Sst 4 staining in islets was not detectable. For immunohistochemical controls, the primary antibody was either omitted or adsorbed for $2 \mathrm{~h}$ at room temperature with $10 \mu \mathrm{g} / \mathrm{ml}$ of the peptide used for immunisations.

Two independent investigators evaluated all immunohistochemical stainings. All sections were scored by means of the immunoreactivity score (IRS) according to Remmele \& Stegner (37), noting the intensity of the colour as well as the percentage of cells showing a positive cytoplasmic staining or staining of the cell membranes. The percentage of positive cells was calculated as follows: no positive cells (0); $<10 \%$ positive cells (1); $10-50 \%$ positive cells $(2) ; 51-80 \%$ positive cells (3); and $>80 \%$ positive cells (4). For the intensity of staining: no staining (0); mild staining (1); moderate staining (2); and strong staining (3). The overall IRS was calculated as (percentage of positive cells $) \times$ (intensity of staining), and classified as negative ('-'; IRS 0 and 1), weak expression (positive '+'; IRS 2 and 3), moderate expression (positive ' + +'; IRS 4-8) or strong expression (positive ' +++ '; IRS 9-12). 


\section{Statistical analysis}

Results are expressed as mean \pm s.e.m. or median (minmax) as appropriate. Statistical differences between the groups were determined by Mann-Whitney $U$ test. Correlations were calculated by $\chi^{2}$-test for dichotomous variables by Fisher's exact $P$ two-sided if numbers were below 7, while Spearman's correlation coefficient was used for interval variables (semi-quantitative analysis). All calculations were performed by Statistica V6 (StatSoft, Hamburg, Germany). A $P$ value $<0.05$ was considered significant. The analysis of the GH doseresponse was performed by GraphPad Prism software (La Jolla, CA, USA) with a sigmoidal dose-response curve fitting model where $Y=$ Bottom $+(($ Top - Bottom $) /(1+10$ $\left.\left.\left(\left(\log I C_{50}-X\right)\right)\right)\right)$ and where $X$ is the logarithm of the concentration and $Y$ is the response concentration; $Y$ starts at Bottom and goes to Top with a sigmoid shape.

\section{Results}

\section{Adenoma characterisation}

Twenty-five of the 27 adenomas (93\%) were positive for GH expression, while two (nos 65 and 72) were classified as $\mathrm{GH}$-secreting adenomas due to the presence of fibrous bodies, characteristic morphology and GH secretion in vitro (Table 1). The majority of the adenomas were negative for ACTH, LH, FSH, TSH and PRL and were classified accordingly as monohormonal. Five adenomas demonstrated additional positivity for PRL and hence were defined as bihormonal for GH and PRL (nos 72, 75, 76, 81 and 89). Granularity was characterised as either dense $(n=15)$ or sparse $(n=12)$ and was almost equally distributed (Table 1).

\section{Sst protein expression}

Sst expression was investigated in 18 of the $21(86 \%)$ adenomas of the dose-response experiments (Table 1). Eleven of the eighteen (61\%) were positive for sst1 and 15 of the $18(83 \%)$ were positive for sst $2 \mathrm{~A}$. Sst 3 and sst 5 were expressed in all adenomas while sst 4 immunoreactivity was positive in eight of the 18 (44\%) adenomas. Individual IRSs are indicated in Table 1. Examples of positive immunoreactivity to sst are given in Fig. 1. For further details on intensity of staining and percentage of positive cells see Supplementary Table 2, see section on supplementary data given at the end of this article.

\section{Basal GH secretion}

The basal GH secretion varied considerably between tumours (Table 1). In the dose-response study it was $156 \mu \mathrm{g} / \mathrm{l}$ (6.5-849.3; median, range). The basal GH secretion was independent of the pre-operative treatment strategy (SSA-pre-treated vs therapy-naïve, $r=-22, P=\mathrm{NS}$ ), the adenomas' hormonal expression pattern (mono- vs bihormonal, $r=-0.1049, P=N S$ ), granularity of the tumour tissue (densely vs sparsely, $r=-0.4191, P=\mathrm{NS}$ ), as well as the IRS of sst1-sst5. In addition, the individual cell cultures' cell numbers, counted immediately before the addition of SSA (data not shown), were unrelated to the basal GH concentration of each adenoma, indicating the high variability of $\mathrm{GH}$ secretion by the individual tumour cells.

\section{Suppression of GH by SSA is time- and dose-dependent}

Six adenomas were used for the time-series experiments. Suppression of GH secretion increased with time in three of the six adenomas responsive to either SSA

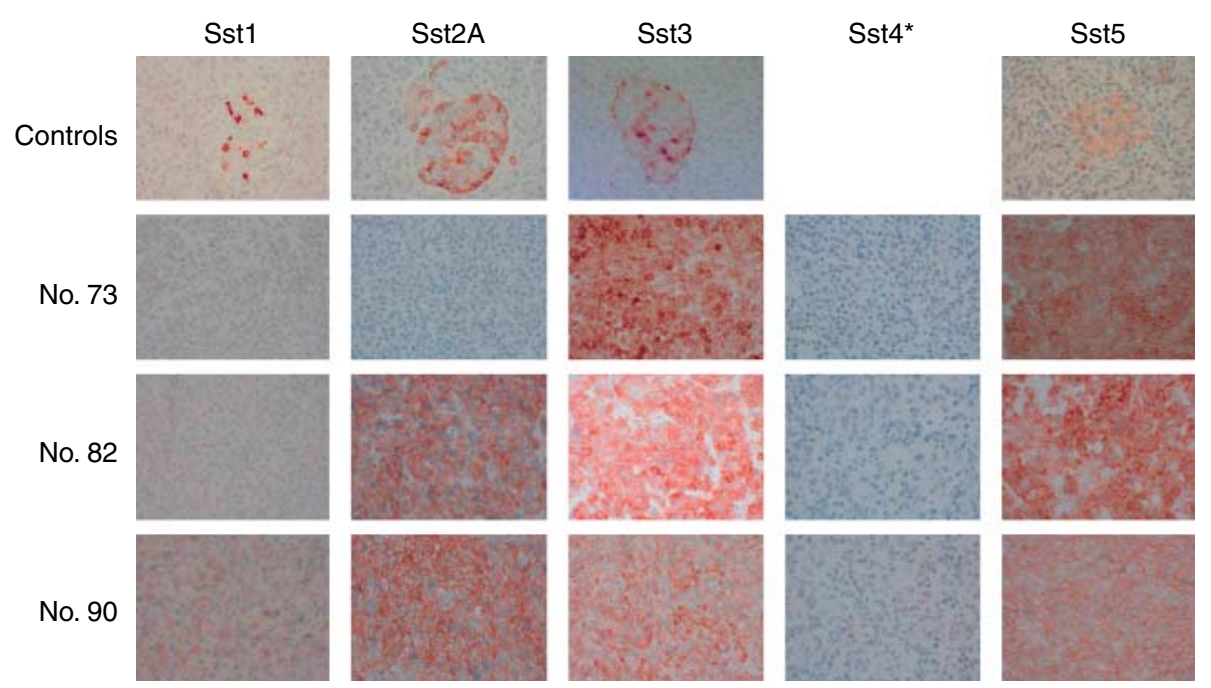

Figure 1 Immunohistochemical expression of sst1, sst2A, sst3, sst4 and sst5. Examples (adenoma nos 73,82 and 90 ) of specific staining for each sst are shown. Pancreatic islets were used as positive control for staining with antibodies to sst1, sst2A, sst3 and sst5. Sst4 staining in islets was not detectable. 

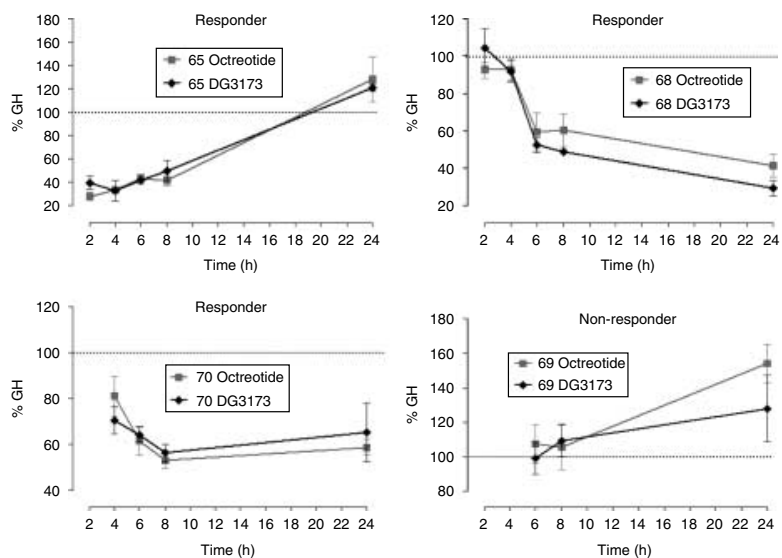

Figure 2 Time-course experiments. Time-dependent decline of the $\mathrm{GH}$ concentration in the three responders (\% of baseline; adenoma nos 65, 68 and 70) and one non-responder (adenoma no. 69) after incubation with DG3173 $(1 \mu \mathrm{M}$, grey line) or Octreotide $(1 \mu \mathrm{M}$, black line). Results are expressed as the mean ( \pm s.E.M.; three wells per time point) $\mathrm{GH}$ suppression relative to baseline. The dashed line indicates the baseline, set as $100 \%$, the crossing with the $y$-axis representing the start of the experiment.

(nos 65, 68 and 70, Table 1 and Fig. 2) and was significantly suppressed to levels below $80 \%$ of baseline at $6 \mathrm{~h}$. Hence, this time interval was used for the consecutive dose-response study. A dose-dependent (range $10^{-12}$ to $10^{-6} \mathrm{M}$ for both SSA) suppression of $\mathrm{GH}$ could be demonstrated in responsive adenomas (examples are given in Fig. 3). Dose-response curves could not be generated from the other responsive adenomas due to insufficient cell material. The individual $\mathrm{IC}_{50}$ values varied by up to $2 \mathrm{log}$ magnitudes, reflecting the heterogeneity of these adenomas (Table 3). Although the median $\mathrm{IC}_{50}$ value for DG3173 was about 1 log magnitude lower than for Octreotide, the range for both SSA was similar. Maximum GH suppression was achieved with either $100 \mathrm{nM}$ or $1 \mu \mathrm{M}$ of DG3173 or Octreotide respectively (Fig. 4).

\section{DG3173 suppresses GH secretion in a larger number of adenomas compared with Octreotide}

Treatment with DG3173 achieved GH suppression to at least $80 \%$ of baseline in a larger number of adenomas than Octreotide (DG3173 vs Octreotide: 10/21, 48\% vs $5 / 21,24 \% ; P=\mathrm{NS}$, Table 1). Whereas the difference failed to be significant, the distribution of GH suppression was found to be interesting, since six nonresponders to Octreotide (nos 72, 80, 81, 83, 90 and 91) demonstrated a positive response to DG3173, and only one adenoma that was responsive to Octreotide was nonresponsive to DG3173 (no. 76). In responding adenomas the extent of the GH-lowering effect was similar for DG3173 and Octreotide respectively (per cent of basal GH conc., mean \pm s.E.M., DG3173: $66.6 \% \pm 4.4$, Octreotide: $64.9 \% \pm 5.4, P=$ NS, Table 1$)$.

\section{Analysis of factors that might influence tumour response to SSA}

Pre-operative therapy with SSA Pre-operative Octreotide therapy did not affect GH suppression by either SSA. Of six out of 21 adenomas (dose-response experiment) with pre-operative SSA therapy, four of the six $(67 \%)$ and two of the six (33\%) responded to DG3173 and Octreotide respectively. Similarly, of 15 out of 21 therapy-naïve adenomas, six of the $15(40 \%)$ and three of the $15(20 \%)$ responded to DG3173 and Octreotide respectively. Thus, neither the number of responding adenomas, nor the extent of the $\mathrm{GH}$ suppression (Table 1), was influenced by pre-operative SSA treatment (Table 4) and this result was confirmed if only those tumours with a significant decline of the $\mathrm{GH}$ concentration were considered.

\section{Hormone expression and morphology of the ade-} noma In both, mono- and bihormonal adenomas, a response to SSA was observed more often for DG3173 than for Octreotide (monohormonal: $8 / 16$, 50\% vs
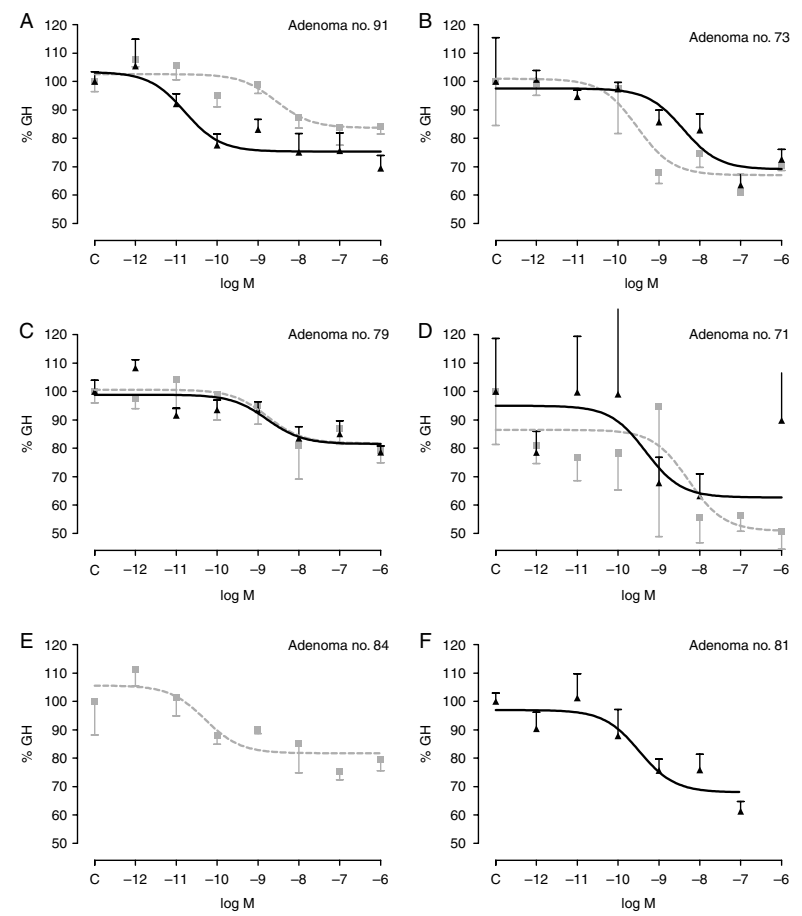

Figure 3 Dose-response experiments. Individual dose-response curves for the inhibition of GH secretion by SSA titrated from $10^{-12}$ to $10^{-6} \mathrm{M}$ in six adenoma cell cultures. A dose-dependent suppression of $\mathrm{GH}$ secretion (\% of baseline) by both SSA (DG3173, triangles and black line; Octreotide, squares and grey line) was observed in four adenomas (A-D; adenoma nos 71, 73, 79 and 91). $\mathrm{GH}$ secretion was dose-dependently suppressed in one additional adenoma, respectively, by either Octreotide (E; adenoma no. 84) or DG3173 (F; adenoma no. 81; bihormonal). Results are expressed as the mean ( \pm S.E.M.) $\mathrm{GH}$ suppression relative to baseline $(\mathrm{C}$, Control=baseline; medium alone). The corresponding $I_{50}$ values are shown in Table 3. 
Table 3 Summary of adenomas with dose-dependent suppression of $\mathrm{GH}$.

\begin{tabular}{lll}
\hline & \multicolumn{2}{c}{ IC $_{\mathbf{5 0}}$} \\
\cline { 2 - 3 } Adenoma & DG3173 & \multicolumn{1}{c}{ Octreotide } \\
\hline Number & & \\
71 & $4.9 \times 10^{-10}$ & $5.3 \times 10^{-9}$ \\
73 & $3.9 \times 10^{-9}$ & $2.9 \times 10^{-10}$ \\
79 & $1.7 \times 10^{-9}$ & $1.7 \times 10^{-9}$ \\
81 & $3.3 \times 10^{-10}$ & $-\mathrm{a}$ \\
84 & $-\mathrm{a}$ & $5.0 \times 10^{-11}$ \\
91 & $1.6 \times 10^{-11}$ & $2.8 \times 10^{-9}$ \\
Summary & & 5 \\
$n$ & 5 & $2.03 \times 10^{-9}$ \\
Mean & $1.28 \times 10^{-9}$ & $2.14 \times 10^{-9}$ \\
S.D. & $1.59 \times 10^{-9}$ & $1.70 \times 10^{-9}$ \\
Median & $4.90 \times 10^{-10}$ & $5.0 \times 10^{-11} / 5.3 \times 10^{-10}$ \\
Range ${ }^{\mathrm{b}}$ & $1.6 \times 10^{-11} / 3.9 \times 10^{-10}$ & \\
\hline
\end{tabular}

${ }^{\mathrm{a} N o}$ dose-dependency could be established.

${ }^{\mathrm{b}} 5$ th/95thpercentile.

$4 / 16,25 \%$; bihormonal $2 / 5,40 \%$ vs $1 / 5,20 \%$, respectively), however this was not significant. Overall, hormonal expression (mono- vs bihormonal) did not influence the response to either SSA (Table 4) and this result was confirmed if only those tumours with a significant decline of the $\mathrm{GH}$ concentration were considered.

In addition to hormonal expression, cell granularity was assessed as a morphological parameter that might influence the response of tumour tissue to SSA. DG3173 induced a positive response significantly more often in sparsely than densely granulated adenomas $\left(\chi^{2}=10.75, \quad P=0.002\right)$, while no such correlation occurred with Octreotide (Table 4). Overall, sparsely granulated adenomas demonstrated a larger number of positive responses to SSA compared with densely granulated adenomas $\left(\chi^{2}=5.84, P=0.023\right)$ and again these results were confirmed if only those tumours with a significant decline of the GH concentration were considered $\left(\chi^{2}=7.988, P=0.009\right)$.

Sst status Eighteen adenomas were available for the evaluation of sst expression. Here DG3173 achieved a positive response in a larger number of adenomas than Octreotide in each of the sst-subtype positive adenomas. Analysing sst subtypes for their correlation to the $\mathrm{GH}$ response for each of the SSA indicated a correlation between the presence of sst1 and the $\mathrm{GH}$ response to DG3173 $\left(\chi^{2}=7.9, P=0.009\right)$ and sst 2 and the $\mathrm{GH}$ response to Octreotide $\left(\chi^{2}=9.36, P=0.012\right.$; Table 4$)$. This relationship failed to be significant if only adenomas with a significant decline of the GH concentration were considered. Due to the dichotomous nature of the variables these statistical results do not indicate the direction of the relationship (positive or negative correlation).

A semi-quantitative approach using the calculated IRSs (ranging from 0 to 12) and the per cent decline of the GH concentration was then used (Spearman's correlation coefficient). This showed a negative correlation between the IRS for sst 2 and the per cent decline of the GH concentration induced by Octreotide (Spearman's $r=-0.565, P<0.02$ ), while no such correlation was found for DG3173. No other significant correlations were observed between the extent of $\mathrm{GH}$ inhibition by either SSA and the IRS of sst expression.

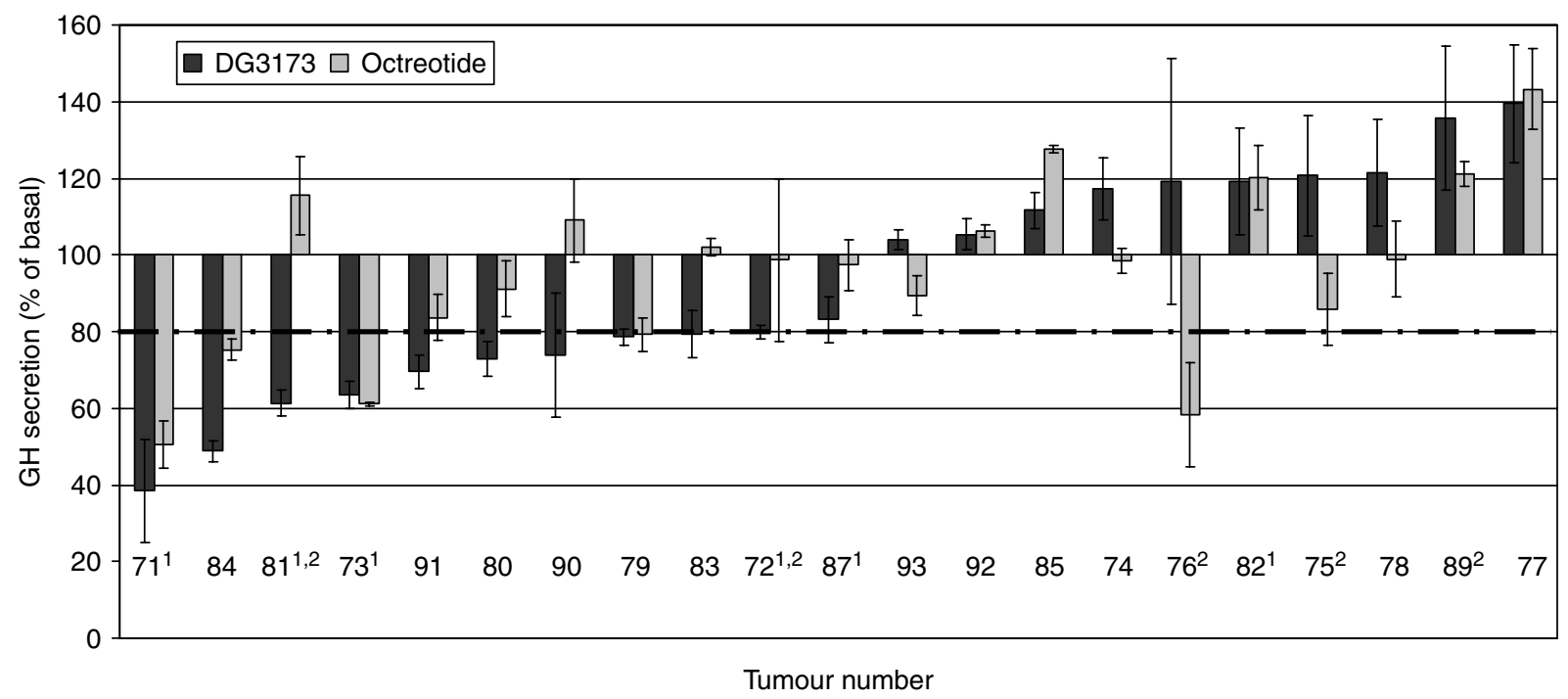

Figure $4 \mathrm{GH}$ suppression by either DG3173 or Octreotide. GH secretion (\% of baseline) in adenoma cell cultures $(n=21)$. Maximal suppression of GH in adenomas responsive to DG3173 (black bars) or to Octreotide (grey bars) at $100 \mathrm{nM}$ or $1 \mu \mathrm{M}$ incubated for $6 \mathrm{~h}$. Results are expressed as the mean ( \pm s.E.M.; 3-6 wells per concentration) GH suppression relative to control. Response was defined as GH suppression to at least $80 \%$ of baseline or less (dashed line). ${ }^{1}$ Patients pre-treated with SSA (see Table 1 ); ${ }^{2}$ bihormonal adenomas (see Table 1). 
Table 4 Summary of variables affecting response to SSA treatment in pituitary adenoma cultures in vitro.

\begin{tabular}{|c|c|c|c|c|}
\hline \multirow[b]{2}{*}{ Variable/subgroup } & \multicolumn{2}{|c|}{ Response $^{a}$} & \multicolumn{2}{|c|}{$P^{\mathrm{b}}$} \\
\hline & DG3173 $(n=10)$ & Octreotide $(n=5)$ & DG3173 & Oct. \\
\hline \multicolumn{5}{|l|}{ Pre-operative treatment } \\
\hline SSA-treated $(n=6)$ & $4(66.7)$ & $2(33.3)$ & NS & NS \\
\hline SSA-naïve $(n=15)$ & $6(40.0)$ & $3(20.0)$ & & \\
\hline \multicolumn{5}{|l|}{ Hormonal expression } \\
\hline Monohormonal $(n=16)$ & $8(50.0)$ & $4(25.0)$ & NS & NS \\
\hline Bihormonal $(n=5)$ & $2(40.0)$ & $1(20.0)$ & & \\
\hline \multicolumn{5}{|l|}{ Morphology } \\
\hline Sparse $(n=9)$ & $8(88.8)$ & $3(33.3)$ & $\chi^{2}=10.75$ & NS \\
\hline Dense $(n=12)$ & $2(16.7)$ & $2(16.7)$ & $\stackrel{\hat{P}}{P}=0.002$ & \\
\hline \multicolumn{5}{|l|}{ Sst protein expression ${ }^{c}$} \\
\hline Sst1 negative $(n=7)$ & $1(14.3)$ & $1(14.3)$ & $\chi^{2}=7.9$ & NS \\
\hline Sst1 positive $(n=11)$ & $9(81.8)$ & $4(36.4)$ & $\stackrel{P}{P}=0.009$ & \\
\hline Sst2A negative $(n=3)$ & $2(66.6)$ & $3(100.0)$ & NS & $\chi^{2}=9.36$ \\
\hline Sst2A positive $(n=15)$ & 8 (53.3) & $2(13.3)$ & & $\hat{P}=0.012$ \\
\hline Sst3 negative $(n=0)$ & 0 & 0 & NA & NA \\
\hline Sst3 positive $(n=18)$ & $10(55.6)$ & $5(27.8)$ & & \\
\hline Sst4 negative $(n=10)$ & $5(50.0)$ & $2(20.0)$ & NS & NS \\
\hline Sst4 positive $(n=8)$ & $5(62.5)$ & $3(37.5)$ & & \\
\hline Sst5 negative $(n=0)$ & 0 & 0 & NA & NA \\
\hline Sst5 positive $(n=18)$ & $10(55.6)$ & $5(27.8)$ & & \\
\hline
\end{tabular}

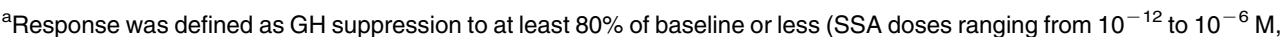
where available).

${ }^{b} \chi^{2}$ by Fisher's two-sided test (NS, not significant; NA, not applicable).

${ }^{\mathrm{C}}$ For classification of sst expression see Methods section.

\section{Discussion}

The clinically available SSA Octreotide and Lanreotide are the first-line medical therapy in acromegalic patients not cured by surgery (2). However, SSA therapy results in suppression of the $\mathrm{GH}$ concentration to $<2.5 \mu \mathrm{g} / \mathrm{l}$ in only $48-58 \%$ of the patients (4) with suppression of insulin as an unwanted side effect $(5,6)$.

Sst distribution in somatotroph adenomas is heterogeneous and even varies in individual tumours, and thus SSA with a broad range of sst binding may prove clinically useful. BIM-23244, an SSA with high-affinity binding to sst2 and sst 5 receptors, has higher efficacy in GH suppression in vitro than Octreotide (38). DG3173 is a new SSA that binds to sst2 and sst5, and also binds with nanomolar affinity to sst4. Importantly, it has only low insulin-suppressing activity (24). Thus, DG3173 may prove to be at least as efficient, as well as even more specific as already existing SSA. In contrast, another new SSA SOM230 with a broad range of sst binding has been shown to substantially inhibit insulin secretion in vivo $(14,20,39,40)$.

The GH-antagonist pegvisomant normalised the IGF1 concentration in up to $97 \%$ of patients under study conditions $(41,42)$. In contrast, long-term observational data describe a significantly lower percentage of IGF1 normalisation ( 72 and $58 \%$ ) after 4 and 5 years of therapy respectively $(43,44)$. However, the risk of tumour regrowth is still of concern in patients with tumour remnants (45). Additional possible side effects are the abolition of any $\mathrm{GH}$ effect, with lipohypertrophy at injection sites and an increase in intra-abdominal fat mass $(46,47,48)$.
In conclusion, there is still need for an effective treatment of acromegaly without the side effects occurring with current therapies.

We herein report the in vitro effect of DG3173 in a large number of somatotroph adenomas, extending a previous report (24). In addition, we investigated possible correlations of GH suppression with presurgical SSA therapy, hormonal expression of the tumour, tumour morphology and sst expression.

Overall DG3173 suppressed GH secretion with a similar efficacy, yet in a larger number of tumours, than Octreotide. Interestingly, it proved to be effective in some tumours that did not respond to Octreotide at all, suppressing GH in 38\% (6/16) of Octreotide nonresponders. Similar effects have already been described for SOM230 which has a 30, 5 and 40 times higher binding affinity to sst1, sst 3 and sst5 receptors, respectively, and 2.5 times lower affinity to sst2 (20). By comparing reports from the literature on the efficacy of SOM230 with our results, a similar number of tumours responded to both Octreotide and SOM230, with GH suppression in seven of the nine (Octreotide) and eight of the nine (SOM230), rendering SOM230 only slightly more effective than Octreotide (49). In contrast DG3173 suppressed GH in six adenomas, non-responsive to Octreotide, indicating a broader range of responsive adenomas compared with Octreotide.

Overall, in this experimental setting, DG3173 was slightly more efficacious than Octreotide in suppressing GH secretion in terms of $\mathrm{IC}_{50}\left(\mathrm{IC}_{50}: 0.49\right.$ vs $1.7 \mathrm{nM}$, DG3173 vs Octreotide), with a broad range in individual adenomas for both SSA. A similar efficacy 
has been reported, with $\mathrm{IC}_{50}$ in nanomolar concentrations for both Octreotide and SOM230, where the $\mathrm{IC}_{50}$ of SOM230 was slightly above that of Octreotide (50). Comparing these data it seems possible that DG3173 might effectively reduce $\mathrm{GH}$ secretion in a larger number of somatotroph adenomas at even lower drug concentrations than both Octreotide and SOM230 respectively. However, a direct comparison of DG1373 and SOM230 has not yet been reported. Nevertheless, if our results are confirmed DG3173 may be a clinical alternative to the available SSA, as more patients might demonstrate GH suppression than with Octreotide.

In an attempt to identify possible predictors of DG3173 efficacy in suppressing GH secretion we investigated several parameters that might influence SSA effects in vitro.

\section{Pre-operative therapy with SSA}

Pre-operative SSA treatment had no effect on the number of responding tumours, or the degree of $\mathrm{GH}$ suppression, by either of the analogues. In seven patients that underwent pre-operative SSA therapy, long-acting SSA were used in all but one patient. However, a persistent drug effect on in vitro $\mathrm{GH}$ secretion is highly unlikely, due to washing and diluting effects during the preparation of the cell cultures.

\section{Hormone expression and morphology of the adenoma}

Tumour responsiveness to either SSA was independent of histo-morphological parameters, i.e. hormone expression (only GH or GH plus PRL expression). Saveanu et al. (51) investigated eleven GH-secreting adenomas including seven somatolactotroph tumours. In their investigations the GH-suppressing effect of Octreotide was independent of the hormonal status of the adenoma, but related to the expression of sst2 mRNA. In a mixed gonadotroph adenoma Lanreotide was effective in reducing $\mathrm{LH}, \boldsymbol{\alpha}$-subunit and PRL secretion due to a high expression of sst 2 and sst5 mRNA (52). Casarini et al. (53) found a differential expression of sst mRNA in mono- vs bihormonal GH-secreting adenomas. However, no analysis was performed with respect to the response to SSA therapy for mono- vs bihormonal tumours. There are only few data available relating the immunohistochemical expression of both, pituitary hormones and sst, indicating a similar pattern of sst distribution for both mono- and bihormonal adenomas (29). No reports are available that correlate these findings to the tumour response to SSA therapy. The pattern of hormone expression is a specific characteristic of any given pituitary tumour and may thus well influence the distribution of sst receptors. Since we could not demonstrate a significant correlation between the $\mathrm{GH}$ decline and hormone expression, its possible influence on the immunohistochemical presence of sst and remains to be further elucidated.

GH-secreting adenomas are sub-classified into either densely or sparsely granulated tumours, with a disputed tendency for more aggressive behaviour, including increased hormone secretion, proliferation and recurrence after surgery in sparsely granulated adenomas (54). In our series both types of adenomas were well represented. The significant positive correlation of a positive response for DG3173 with sparsely granulated tumours was not evident for Octreotide. However, lack of significance may be due to the small numbers in this subgroup. Our data are in contrast to reports from the literature. Stefaneanu et al. (55) demonstrated a mild decrease of the $\mathrm{GH}$ and sst2 mRNA signals in the densely granulated adenomas of 14 somatotropinomas with pre-operative Octreotide therapy. The authors concluded that densely granulated adenomas may have a more favourable response to Octreotide therapy than sparsely granulated adenomas. Thodou et al. (56) described higher $\mathrm{GH}$ secretion in densely $(n=5)$ compared with sparsely $(n=5)$ granulated somatotroph adenomas. In a semi-quantitative in vitro-approach, using reverse haemolytic plaque assays (rHPA) for the determination of $\mathrm{GH}$ secretion, in those six tumours treated with Octreotide the GH secretion was preferentially reduced in the densely granulated adenomas. Bhayana et al. (57) investigated the correlation of adenoma morphology to subsequent in vivo Octreotide therapy in 40 acromegalic patients, including $23 \%$ with irradiation before SSA therapy. The presence of a dense granulation was a significant predictor of complete remission. However, using Kaplan-Meier analysis, with the time interval to complete remission as an endpoint and densely vs sparsely granulated adenomas as variables, this relationship failed to be significant. These different approaches using either GH mRNA, rHPA as an indicator of $\mathrm{GH}$ secretion or in vivo $\mathrm{GH}$ secretion are not strictly comparable to our investigation as we compare in vitro morphological data to quantitative determination of the in vitro $\mathrm{GH}$ secretion. In our investigation the overall distribution of sst was not significantly different between sparsely and densely granulated adenomas. Thus, it is conceivable that the granularity of the adenoma is related to specific tumour characteristics that either support or reduce the GH-suppressing effect of SSA in these adenomas. However, larger series of $\mathrm{GH}$-secreting adenomas will have to be analysed to confirm this hypothesis.

\section{Somatostatin receptors}

The qualitative analysis (presence/absence of sst vs presence/absence of a positive response to each of the SSA) confirmed a correlation between sst 2 receptor expression at the protein level and the GH-lowering effect of Octreotide, as has also been demonstrated by others $(26,58)$. A semi-quantitative (expression of sst 
quantified by IRS vs per cent decline of the GH concentration for each SSA) analysis revealed a negative correlation of the IRS for sst2 and the per cent GH decline induced by Octreotide. No further correlations were evident for the other ssts and Octreotide or any sst and DG3173. This may in part be due to the small number of adenomas in each of the relevant ssts subgroups. However, the negative correlation of the IRS with the GH decline induced by Octreotide is unexpected. This may indicate that either the IRS may not fully represent the functional activity of the ssts or that the GH-lowering effect is transferred via functional interaction with more than one sst. Furthermore, sst may form homo- and heterodimers, and this may modify the functional properties of the receptors and result in higher efficacy (9). In addition, heterodimerisation of the different ssts upon binding would preclude any clear-cut correlation between receptor expression and signal transduction after ligand binding in multiligand SSA $(9,10)$. We have previously demonstrated a lack of correlation between the results of sst scintigraphy (reflecting sst2-status of the adenoma) and the effect of Octreotide on GH secretion or tumour shrinking in acromegaly (59).

In conclusion DG3173, a new SSA with a unique binding pattern to sst, suppresses GH in most Octreotide-responsive somatotroph adenomas as well as in a large number of tumours not responding to Octreotide, thus expanding the range of tumours that can be possibly treated with SSA. In addition, others $(24,30)$ demonstrated the weak effect of DG3173 on insulin secretion. Should our in vitro results on GH secretion be confirmed in clinical studies, then the combination of these two effects would be a strong argument for the use of DG3173 in acromegalic patients not cured by surgery.

\section{Supplementary data}

This is linked to the online version of the paper at http://dx.doi.org/10. 1530/EJE-11-0737.

\section{Declaration of interest}

U Plöckinger, U Hoffmann, M Geese, A Lupp, J Flitsch, M Buchfelder, P Vajkoczy, W Jakob, W Saeger, S Schulz and C Dohrmann have nothing to declare. U Hoffmann, M Geese and C Dohrmann are employees of Develogen.

\section{Funding}

This research did not receive any specific grant from any funding agency in the public, commercial or not-for-profit sector.

\section{Author contribution statement}

U Plöckinger and U Hoffmann designed, performed and supervised the in vitro investigation, calculated the data and wrote the manuscript. M Geese supervised the GH assays and prepared all figures. W Saeger, A Lupp and S Schulz performed the immunohistochemical analysis on pituitary hormones (S Schulz) and somatostatin receptors (A Lupp and S Schulz). M Buchfelder, J Flitsch and P Vajkoczy provided the tumour tissue. W Jakob helped with patient identification, recruitment and clinical data collection of the Berlin patients. All authors provided critical comments and a final approvement of the manuscript.

\section{Acknowledgements}

We thank Monique Erling and Christina Kothe for GH ELISA analyses (DeveloGen AG), and Ines Eichhorn for adenoma tissue preparation and cell culture experiments (Stoffwechsel-Centrum, Charité). The following neuropathologists have contributed to the publication by allowing us to use part of the adenoma tissue for these experiments: Prof. Dr Frank Heppner (Institut für Neuropathologie, ChariteUniversitätsmedizin Berlin) and Prof. Dr med. Rolf Buslei (Institut für Neuropathologie, Universität Erlangen-Nürnberg).

\section{References}

1 Buchfelder M \& Schlaffer S. Surgical treatment of pituitary tumours. Best Practice \& Research. Clinical Endocrinology $\mathcal{E}$ Metabolism 200923 677-692. (doi:10.1016/j.beem.2009.05. 002)

2 Cook DM, Ezzat S, Katznelson L, Kleinberg DL, Laws ER Jr, Nippoldt TB, Swearingen B \& Vance ML. AACE Medical Guidelines for Clinical Practice for the diagnosis and treatment of acromegaly. Endocrine Practice 2011 Suppl 4 1-44. (doi:10.4158/11215.OR)

3 Ben-Shlomo A \& Melmed S. Somatostatin agonists for treatment of acromegaly. Molecular and Cellular Endocrinology 2008286 192-198. (doi:10.1016/j.mce.2007.11.024)

4 Freda PU, Katznelson L, van der Lely AJ, Reyes CM, Zhao S \& Rabinowitz D. Long-acting somatostatin analog therapy of acromegaly: a meta-analysis. Journal of Clinical Endocrinology and Metabolism 200590 4465-4473. (doi:10.1210/jc.2005-0260)

5 Plockinger U, Holst JJ, Messerschmidt D, Hopfenmuller W \& Quabbe HJ. Octreotide suppresses the incretin glucagon-like peptide (7-36) amide in patients with acromegaly or clinically nonfunctioning pituitary tumors and in healthy subjects. European Journal of Endocrinology 1999140 538-544. (doi:10.1530/eje.0. 1400538)

6 Mazziotti G, Floriani I, Bonadonna S, Torri V, Chanson P \& Giustina A. Effects of somatostatin analogs on glucose homeostasis: a metaanalysis of acromegaly studies. Journal of Clinical Endocrinology and Metabolism 200994 1500-1508. (doi:10. 1210/jc.2008-2332)

7 Singh V, Brendel MD, Zacharias S, Mergler S, Jahr H, Wiedenmann B, Bretzel RG, Plockinger U \& Strowski MZ. Characterization of somatostatin receptor subtype-specific regulation of insulin and glucagon secretion: an in vitro study on isolated human pancreatic islets. Journal of Clinical Endocrinology and Metabolism 200792 673-680. (doi:10.1210/jc.2006-1578)

8 Strowski MZ \& Blake AD. Function and expression of somatostatin receptors of the endocrine pancreas. Molecular and Cellular Endocrinology 2008286 169-179. (doi:10.1016/j.mce.2008. 02.007)

9 Duran-Prado M, Malagon MM, Gracia-Navarro F \& Castano JP. Dimerization of $\mathrm{G}$ protein-coupled receptors: new avenues for somatostatin receptor signalling, control and functioning. Molecular and Cellular Endocrinology 2008 286 63-68. (doi:10. 1016/j.mce.2007.12.006)

10 Olias G, Viollet C, Kusserow H, Epelbaum J \& Meyerhof W. Regulation and function of somatostatin receptors. Journal of Neurochemistry 200489 1057-1091. (doi:10.1111/j.14714159.2004.02402.x)

11 Poll F, Lehmann D, Illing S, Ginj M, Jacobs S, Lupp A, Stumm R \& Schulz S. Pasireotide and octreotide stimulate distinct patterns of sst2A somatostatin receptor phosphorylation. Molecular Endocrinology 201024 436-446. (doi:10.1210/me.2009-0315) 
12 Ma P, Wang Y, van der Hoek J, Nedelman J, Schran H, Tran LL \& Lamberts SW. Pharmacokinetic-pharmacodynamic comparison of a novel multiligand somatostatin analog, SOM230, with octreotide in patients with acromegaly. Clinical Pharmacology and Therapeutics 200578 69-80. (doi:10.1016/j.clpt.2005.04.003)

13 Plockinger U, Albrecht S, Mawrin C, Saeger W, Buchfelder M, Petersenn S \& Schulz S. Selective loss of somatostatin receptor 2 in octreotide-resistant growth hormone-secreting adenomas. Journal of Clinical Endocrinology and Metabolism 200893 1203-1210. (doi:10.1210/jc.2007-1986)

14 Petersenn S, Schopohl J, Barkan A, Mohideen P, Colao A, Abs R, Buchelt A, Ho YY, Hu K, Farrall AJ, Melmed S \& Biller BM. Pasireotide (SOM230) demonstrates efficacy and safety in patients with acromegaly: a randomized, multicenter, phase II trial. Journal of Clinical Endocrinology and Metabolism 201095 2781-2789. (doi:10.1210/jc.2009-2272)

15 Petersenn S, Unger N, Hu K, Weisshaar B, Zhang Y, Bouillaud E, Hermosillo Resendiz K, Wang Y \& Mann K. Pasireotide (SOM230), a novel multi-receptor-targeted somatostatin analogue, is well tolerated when administered as a continuous 7-day subcutaneous infusion in healthy male volunteers. Journal of Clinical Pharmacology 2012. In press. (doi:10.1177/0091270011408727)

16 van der Hoek J, de Herder WW, Feelders RA, van der Lely AJ, Uitterlinden $\mathrm{P}$, Boerlin V, Bruns C, Poon KW, Lewis I, Weckbecker G, Krahnke T, Hofland LJ \& Lamberts SW. A singledose comparison of the acute effects between the new somatostatin analog SOM230 and octreotide in acromegalic patients. Journal of Clinical Endocrinology and Metabolism $2004 \mathbf{8 9}$ 638-645. (doi:10.1210/jc.2003-031052)

17 Boerlin V, van der Hoek J, Beglinger C, Poon KW, Hartmann S, Dutreix C, Kovarik JM, Bruns C, Weckbecker G, Lewis I, Schnieper P, Hofland LJ \& Lamberts SW. New insights on SOM230, a universal somatostatin receptor ligand. Journal of Endocrinological Investigation 200326 14-16.

18 Ben-Shlomo A \& Melmed S. Pasireotide - a somatostatin analog for the potential treatment of acromegaly, neuroendocrine tumors and Cushing's disease. IDrugs: the Investigational Drugs Journal 200710 885-895.

19 Schmid HA. Pasireotide (SOM230): development, mechanism of action and potential applications. Molecular and Cellular Endocrinology 2008286 69-74. (doi:10.1016/j.mce.2007.09.006)

20 Bruns C, Lewis I, Briner U, Meno-Tetang G \& Weckbecker G. SOM230: a novel somatostatin peptidomimetic with broad somatotropin release inhibiting factor (SRIF) receptor binding and a unique antisecretory profile. European Journal of Endocrinology 2002146 707-716. (doi:10.1530/eje.0.1460707)

21 Ferone D, Gatto F, Arvigo M, Resmini E, Boschetti M, Teti C, Esposito D \& Minuto F. The clinical-molecular interface of somatostatin, dopamine and their receptors in pituitary pathophysiology. Journal of Molecular Endocrinology 200942 361-370. (doi:10.1677/JME-08-0162)

22 Jaquet P, Gunz G, Saveanu A, Barlier A, Dufour H, Taylor J, Dong J. Kim S, Moreau JP \& Culler MD. BIM-23A760, a chimeric molecule directed towards somatostatin and dopamine receptors, vs universal somatostatin receptors ligands in GH-secreting pituitary adenomas partial responders to octreotide. Journal of Endocrinological Investigation 200528 21-27.

23 Jaquet P, Gunz G, Saveanu A, Dufour H, Taylor J, Dong J, Kim S, Moreau JP, Enjalbert A \& Culler MD. Efficacy of chimeric molecules directed towards multiple somatostatin and dopamine receptors on inhibition of $\mathrm{GH}$ and prolactin secretion from GH-secreting pituitary adenomas classified as partially responsive to somatostatin analog therapy. European Journal of Endocrinology 2005153 135-141. (doi:10.1530/eje.1.01950)

24 Afargan M, Janson ET, Gelerman G, Rosenfeld R, Ziv O, Karpov O, Wolf A, Bracha M, Shohat D, Liapakis G, Gilon C, Hoffman A, Stephensky D \& Oberg K. Novel long-acting somatostatin analog with endocrine selectivity: potent suppression of growth hormone but not of insulin. Endocrinology 2001142 477-486. (doi:10. 1210/en.142.1.477)
25 Taboada GF, Luque RM, Bastos W, Guimaraes RF, Marcondes JB, Chimelli LM, Fontes R, Mata PJ, Filho PN, Carvalho DP, Kineman RD \& Gadelha MR. Quantitative analysis of somatostatin receptor subtype (SSTR1-5) gene expression levels in somatotropinomas and non-functioning pituitary adenomas. European Journal of Endocrinology 2007156 65-74. (doi:10.1530/eje.1. 02313)

26 Taboada GF, Luque RM, Neto LV, Machado Ede O, Sbaffi BC, Domingues RC, Marcondes JB, Chimelli LM, Fontes R, Niemeyer P, de Carvalho DP, Kineman RD \& Gadelha MR. Quantitative analysis of somatostatin receptor subtypes (1-5) gene expression levels in somatotropinomas and correlation to in vivo hormonal and tumor volume responses to treatment with octreotide LAR. European Journal of Endocrinology 2008158 295-303. (doi:10.1530/EJE07-0562)

27 Pawlikowski M, Pisarek H, Kunert-Radek J \& Radek M. Somatostatin receptors in GH-secreting pituitary adenomas - their relationship to the response to octreotide. Endokrynologia Polska 200859 196-199.

28 Pisarek H, Pawlikowski M, Kunert-Radek J \& Radek M. Expression of somatostatin receptor subtypes in human pituitary adenomas immunohistochemical studies. Endokrynologia Polska 200960 240-251.

29 Thodou E, Kontogeorgos G, Theodossiou D \& Pateraki M. Mapping of somatostatin receptor types in $\mathrm{GH}$ or/and PRL producing pituitary adenomas. Journal of Clinical Pathology 200659 274-279. (doi:10.1136/jcp.2005.026914)

30 Shimon I, Rubinek T, Hadani M \& Alhadef N. PTR-3173 (somatoprim), a novel somatostatin analog with affinity for somatostatin receptors 2, 4 and 5 is a potent inhibitor of human GH secretion. Journal of Endocrinological Investigation 200427 721-727.

31 Giustina A, Barkan A, Chanson P, Grossman A, Hoffman A, Ghigo E, Casanueva F, Colao A, Lamberts S, Sheppard M \& Melmed S. Guidelines for the treatment of growth hormone excess and growth hormone deficiency in adults. Journal of Endocrinological Investigation 200831 820-838.

32 Tulipano G, Bonfanti C, Milani G, Billeci B, Bollati A, Cozzi R, Maira G, Murphy WA, Poiesi C, Turazzi S \& Giustina A. Differential inhibition of growth hormone secretion by analogs selective for somatostatin receptor subtypes 2 and 5 in human growthhormone-secreting adenoma cells in vitro. Neuroendocrinology 200173 344-351. (doi:10.1159/000054651)

33 Schulz S, Schmitt J, Wiborny D, Schmidt H, Olbricht S, Weise W, Roessner A, Gramsch C \& Hollt V. Immunocytochemical detection of somatostatin receptors sst1, sst2A, sst2B, and sst3 in paraffinembedded breast cancer tissue using subtype-specific antibodies. Clinical Cancer Research 19984 2047-2052.

34 Mawrin C, Schulz S, Hellwig-Patyk A, Kirches E, Roessner A, Lendeckel U, Firsching R, Vorwerk CK, Keilhoff G, Dietzmann K, Grimm K, Lindberg G, Gutmann DH, Scheithauer BW \& Perry A. Expression and function of somatostatin receptors in peripheral nerve sheath tumors. Journal of Neuropathology and Experimental Neurology $2005 \quad 64 \quad 1080-1088 . \quad$ (doi:10.1097/01.jnen. $0000190065.36182 .25)$

35 Fischer T, Doll C, Jacobs S, Kolodziej A, Stumm R \& Schulz S. Reassessment of sst2 somatostatin receptor expression in human normal and neoplastic tissues using the novel rabbit monoclonal antibody UMB-1. Journal of Clinical Endocrinology and Metabolism 200893 4519-4524. (doi:10.1210/jc.2008-1063)

36 Lupp A, Hunder A, Petrich A, Nagel F, Doll C \& Schulz S. Reassessment of sst5 somatostatin receptor expression in normal and neoplastic human tissues using the novel rabbit monoclonal antibody UMB-4. Neuroendocrinology 201194 255-264. (doi:10. 1159/000329876)

37 Remmele W \& Stegner H. Recommendation for uniform definition of an immunoreactive score (IRS) for immunohistochemical estrogen receptor detection (ER-ICA) in breast cancer tissue. Der Pathologe 19878 138-140.

38 Saveanu A, Gunz G, Dufour H, Caron P, Fina F, Ouafik L, Culler MD, Moreau JP, Enjalbert A \& Jaquet P. Bim-23244, a 
somatostatin receptor subtype 2- and 5-selective analog with enhanced efficacy in suppressing growth hormone (GH) from octreotide-resistant human GH-secreting adenomas. Journal of Clinical Endocrinology and Metabolism 2001 86 140-145. (doi:10. 1210/jc.86.1.140)

39 Hofland LJ, van der Hoek J, Feelders R, van der Lely AJ, de Herder W \& Lamberts SW. Pre-clinical and clinical experiences with novel somatostatin ligands: advantages, disadvantages and new prospects. Journal of Endocrinological Investigation $2005 \mathbf{2 8}$ $36-42$.

40 Weckbecker G, Briner U, Lewis I \& Bruns C. SOM230: a new somatostatin peptidomimetic with potent inhibitory effects on the growth hormone/insulin-like growth factor-I axis in rats, primates, and dogs. Endocrinology $2002 \mathbf{1 4 3} 4123-4130$. (doi:10.1210/en.2002-220219)

41 van der Lely AJ, Hutson RK, Trainer PJ, Besser GM, Barkan AL, Katznelson L, Klibanski A, Herman-Bonert V, Melmed S, Vance ML, Freda PU, Stewart PM, Friend KE, Clemmons DR, Johannsson G, Stavrou S, Cook DM, Phillips LS, Strasburger CJ, Hackett S, Zib KA, Davis RJ, Scarlett JA \& Thorner MO. Long-term treatment of acromegaly with pegvisomant, a growth hormone receptor antagonist. Lancet 2001358 1754-1759. (doi:10.1016/ S0140-6736(01)06844-1)

42 Trainer PJ, Drake WM, Katznelson L, Freda PU, Herman-Bonert V, van der Lely AJ, Dimaraki EV, Stewart PM, Friend KE, Vance ML, Besser GM, Scarlett JA, Thorner MO, Parkinson C, Klibanski A, Powell JS, Barkan AL, Sheppard MC, Malsonado M, Rose DR, Clemmons DR, Johannsson G, Bengtsson BA, Stavrou S, Kleinberg DL, Cook DM, Phillips LS, Bidlingmaier M, Strasburger CJ, Hackett S, Zib K, Bennett WF \& Davis RJ. Treatment of acromegaly with the growth hormone-receptor antagonist pegvisomant. New England Journal of Medicine 2000 342 1171-1177. (doi:10.1056/NEJM200004203421604)

43 Buchfelder M, Schlaffer S, Droste M, Mann K, Saller B, Brubach K, Stalla GK \& Strasburger CJ. The German ACROSTUDY: past and present. European Journal of Endocrinology 2009161 (Suppl 1) S3-S10. (doi:10.1530/EJE-09-0350)

44 Brue T. ACROSTUDY: status update on 469 patients. Hormone Research 200971 (Suppl 1) 34-38. (doi:10.1159/000178035)

45 Marazuela M, Paniagua AE, Gahete MD, Lucas T, AlvarezEscola C, Manzanares R, Cameselle-Teijeiro J, Luque-Ramirez M, Luque RM, Fernandez-Rodriguez E, Castano JP \& Bernabeu I. Somatotroph tumor progression during pegvisomant therapy: a clinical and molecular study. Journal of Clinical Endocrinology and Metabolism 2011 96 E251-E259. (doi:10.1210/jc.2010-1742)

46 Plockinger U \& Reuter T. Pegvisomant increases intra-abdominal fat in patients with acromegaly: a pilot study. European Journal of Endocrinology 2008158 467-471. (doi:10.1530/EJE-07-0637)

47 Maffei P, Martini C, Pagano C, Sicolo N \& Corbetti F. Lipohypertrophy in acromegaly induced by the new growth hormone receptor antagonist pegvisomant. Annals of Internal Medicine 2006 145 310-312.

48 Marazuela M, Dauden E, Ocon E, Moure D \& Nattero L. Pegvisomant-induced lipohypertrophy: report of a case with histopathology. Annals of Internal Medicine 2007 147 741-743.

49 Feelders RA, Hofland LJ, van Aken MO, Neggers SJ, Lamberts SW, de Herder WW \& van der Lely AJ. Medical therapy of acromegaly: efficacy and safety of somatostatin analogues. Drugs 200969 2207-2226. (doi:10.2165/11318510-000000000-00000)

50 Hofland LJ, van der Hoek J, van Koetsveld PM, de Herder WW, Waaijers M, Sprij-Mooij D, Bruns C, Weckbecker G, Feelders R, van der Lely AJ, Beckers A \& Lamberts SW. The novel somatostatin analog SOM230 is a potent inhibitor of hormone release by growth hormone- and prolactin-secreting pituitary adenomas in vitro. Journal of Clinical Endocrinology and Metabolism $2004 \mathbf{8 9}$ 1577-1585. (doi:10.1210/jc.2003-031344)

51 Saveanu A, Lavaque E, Gunz G, Barlier A, Kim S, Taylor JE, Culler MD, Enjalbert A \& Jaquet P. Demonstration of enhanced potency of a chimeric somatostatin-dopamine molecule, BIM23A387, in suppressing growth hormone and prolactin secretion from human pituitary somatotroph adenoma cells. Journal of Clinical Endocrinology and Metabolism 200287 5545-5552. (doi:10.1210/jc.2002-020934)

52 Saveanu A, Morange-Ramos I, Gunz G, Dufour H, Enjalbert A \& Jaquet P. A luteinizing hormone-, alpha-subunit- and prolactinsecreting pituitary adenoma responsive to somatostatin analogs: in vivo and in vitro studies. European Journal of Endocrinology 2001 145 35-41. (doi:10.1530/eje.0.1450035)

53 Casarini AP, Jallad RS, Pinto EM, Soares IC, Nonogaki S, GiannellaNeto D, Musolino NR, Alves VA \& Bronstein MD. Acromegaly: correlation between expression of somatostatin receptor subtypes and response to octreotide-lar treatment. Pituitary 200912 297-303. (doi:10.1007/s11102-009-0175-1)

54 Saeger W, Ludecke DK, Buchfelder M, Fahlbusch R, Quabbe HJ \& Petersenn S. Pathohistological classification of pituitary tumors: 10 years of experience with the German Pituitary Tumor Registry. European Journal of Endocrinology 2007156 203-216. (doi:10. 1530/eje.1.02326)

55 Stefaneanu L, Kovacs K, Thapar K, Horvath E, Melmed S \& Greenman Y. Octreotide effect on growth hormone and somatostatin subtype 2 receptor mRNAs of the human pituitary somatotroph adenomas. Endocrine Pathology 200011 41-48. (doi:10.1385/EP:11:1:41)

56 Thodou E, Kontogeorgos G, Kyrodimou E, Salla H, Ramyar L, Vamvassakis E, Piaditis G, Anagnastopoulos N, Tzanis S, Levedis A, Rologis D \& Asa SL. Structure-function correlations of growth hormone or/and prolactin-producing pituitary adenomas: an in vitro study with the reverse hemolytic plaque assay. Journal of Endocrinological Investigation 199922 671-680.

57 Bhayana S, Booth GL, Asa SL, Kovacs K \& Ezzat S. The implication of somatotroph adenoma phenotype to somatostatin analog responsiveness in acromegaly. Journal of Clinical Endocrinology and Metabolism 200590 6290-6295. (doi:10.1210/jc.20050998)

58 Acunzo J, Thirion S, Roche C, Saveanu A, Gunz G, Germanetti AL, Couderc B, Cohen R, Figarella-Branger D, Dufour H, Brue T, Enjalbert A \& Barlier A. Somatostatin receptor sst 2 decreases cell viability and hormonal hypersecretion and reverses octreotide resistance of human pituitary adenomas. Cancer Research 200868 10163-10170. (doi:10.1158/0008-5472.CAN-08-1857)

59 Plöckinger U, Bäder M, Hopfenmüller W, Saeger W \& Quabbe HJ. Results of somatostatin receptor scintigraphy do not predict pituitary tumor volume- and hormone-response to ocreotide therapy and do not correlate with tumor histology. European Journal of Endocrinology 1997136 369-376. (doi:10.1530/eje.0. 1360369)

Received 22 August 2011

Revised version received 16 October 2011

Accepted 7 November 2011 